\title{
Data-driven precision agricultural applications using field sensors and Unmanned Aerial Vehicle
}

\author{
Rohit Pathak, Razieh Barzin, Ganesh C. Bora* \\ (Dept. of Agricultural and Biological Engineering, Mississippi State University, Mississippi State, MS 39762, USA)
}

\begin{abstract}
Unmanned Aerial Vehicle (UAVs) and crop sensors are the most widely used remote sensing tool in precision agriculture. Use of UAVs in precision agriculture is attracting increasing interest due to its unique non-destructive approach. In recent years, dramatic evolution of precision agriculture technology has been driven by technologies such as sensors and controllers, telematics, and UAVs. An intriguing area in the field of precision agriculture and UAVs is big volume of data and its analysis that have not been dealt with in depth. The objective of this study was to validate the crop data acquisition procedure and the crop relationship with different type of data acquisition technique. In particular, this paper will compare ground based active optical sensor data collection with UAVs imagery for site-specific nitrogen management. To accomplish these objectives randomized complete block plantation experimental design was used with four treatments and four replicates. The plots were 12 rows wide at 38 " spacing and were $125 \mathrm{ft}$. in length. GreenSeeker field sensor and Micasense sensor for UAVs was used to evaluate the Normalized Difference Vegetation Index. The software used to analyze the data were Microsoft ${ }^{\mathbb{B}}$ Excel $^{\circledR}$ 2013, Statistical Analysis Software (ver.9.4) and ESRI ArcGIS (ver. 10.3). The results showed that UAVs assessed NDVI are good indicator of crop nutrition along with the ground based crop sensors. The result of the statistical data analysis showed that NDVI values are dependent on nitrogen application rate. The average NDVI value for no nitrogen application was recorded 0.54 whereas for $240 \mathrm{lb}$./acre nitrogen application it was noted to be 0.76 . Crucially, this correlation holds true for definite extent of nitrogen application rate. Because there was not any significant change in NDVI for $160 \mathrm{lb}$./acre and $240 \mathrm{lb}$./acre. The NDVI values being 0.74 and 0.76 respectively. The results are significant because it shows the potential of further validating the use of aerial imagery derived NDVI for real time application of crop nutrient. This research has also proven that UAVs are reliable platform for nutrient assessment and making crop management decisions.
\end{abstract}

Keywords: Digital image, NDVI, Nitrogen, ground based sensor, crop

DOI: $10.33440 /$ j.ijpaa.20180101.0004

Citation: Pathak R, Barzin R, Bora G C. Data-driven precision agricultural applications using field sensors and Unmanned Aerial Vehicle (UAVs). Int J Precis Agric Aviat, 2018; 1(1): 19 -23.

\section{Introduction}

The concept and method of farming has changed over the time. The traditional ways of farming, use of animals are becoming obsolete throughout the world. Farming is more of technology dependent these days. Since the introduction of precision agriculture, the total scenario of agriculture has changed. Precision Agriculture according to Cambardella and Karlen ${ }^{[1]}$ is a crop and soil management system that involves application of computer for acquiring and analysis of data and data storage system to collect the required information for site-specific input application. Precision agriculture is the application of right amounts of input (pesticides, herbicides, fertilizers, etc.) at the right time and right place to increase the production, minimize the input and also protect the environment.

\section{Received date: 2018-03-18 Accepted date: 2018-06-27}

Biographies: Rohit Pathak, $\mathrm{PhD}$ candidate, research interests: precision agriculture and UAV, E-mail: rp1265@msstate.edu; Razieh Barzin, PhD candidate, research interests: precision agriculture and data management, E-mail: rb2146@msstate.edu.

*Corresponding author: Ganesh C. Bora, $\mathrm{PhD}$, Associate Professor, research interests: precision agricultural machinery systems, Big-Data, UAV, International Collaborative Engineering. Agricultural and Biological Engineering, Mississippi State University, Mississippi State, MS 39762, USA. Tel: +1-662-325-3155, Email: gcbora@abe.msstate.edu.
According to Cook and Bramley ${ }^{[2]}$ crop is a spatially varied product that depends on variability of location. An automatic data acquisition system developed by Gomide et al. ${ }^{[3]}$, was used for the study of data management and spatial variability in the crop production system. The benefit of precision agriculture does not depend only on quantity of data but also depends on quality of data and method of application. One of the major sources of data are sensors in the field. They are used to measure the physical quantity in the field. Based on the data carriers, sensors can be categorized as mechanical, electrical, optical, acoustic, pneumatic and electromagnetic. These sensors are used to gather information like soil moisture, crop stress, soil properties, nutrients, etc $^{[4]}$. Automatic system was used to collect data of soil water availability, soil compaction, soil fertility, biomass and grain yield, etc $^{[5]}$.

In recent years, dramatic evolution of precision agriculture (PA) technology has been driven by technologies such as sensors and controllers, telematics, and unmanned aerial vehicle (UAVs). The economic impact of UAVs is estimated as $\$ 82 \mathrm{~B}$ in the next 10 years, with over $80 \%$ of it being in the precision agriculture sector $^{[6]}$. In crop production, timely assessment of relevant data is very critical, and the available data sets are too intricate that require extensive knowledge for visualization and information collection ${ }^{[7]}$. The study by Kamilaris et al. ${ }^{[8]}$, shows the various impediments (data collection, delivery and analysis, visualization, spatial resolution, sampling errors, reliability and availability of tool and 
techniques) which still possess a potential of further research and development in the field. The dissemination of information should be based on the type of crop and farmers of the specific area. Based on the capability and credentials of data users (farmers, crop advisors, farm assistants) mobile and web applications are required to be developed ${ }^{[9]}$. The reason behind the dawdling adoption rate of precision agriculture are lack of consistency, ability to exchange and use information, user-friendliness and security measures ${ }^{[10]}$ With major advances in field and equipment-based sensor technology and high-resolution data by UAS the potential to revolutionize agriculture rests on successfully addressing a number of challenges relating to acquiring, understanding, and using Big Data.

Precision farming tools of the modern days are used for collecting spatial information to enhance the efficiency of field work by optimizing the input and minimizing the impact to the environment. The major concern is the integration of all the available field data for quintessential decision support system. Where the issues related to data analysis and support system: protocols, standards, easy to use tool for farmers, researchers and consultant, systematic design for data analysis and integration are addressed in a very precise manner ${ }^{[11]}$. The efficient and productive analysis of big data in precision agriculture sector will help farmers to get rid of field uncertainties. In turn, improving the productivity and reducing the cost of production ${ }^{[12]}$. The use of precision agriculture data in an appropriate manner can influence both the environmental (contamination of soils, nitrogen in ground water, soil erosion) and economical (excessive fertilizer cost) risk reduction ${ }^{[13]}$. There is a need of web-based platform that can handle the high volume and variety of data with an ease. The long-term objective of the project is to develop a web-based computer data processing program to analyze the big data and deliver it in useful format to the farmers in real time or near real time. In his review of current and future advances of precision agriculture, Lan et al. ${ }^{[14]}$, highlights the need of real time image processing, data analysis and interpretation to figure out the influential factor and their relationship. The data acquisition, storage, handling, online data processing and delivery to the farmers. The project also aims to find the identification of delivery mechanism of the processed product such as prescription map, locations or useful imagery to handheld devices such as iPad or iPhone in the field farm equipment. The present paper aims to validate the crop data acquisition procedure and the crop relationship with different type of data acquisition technique. In particular, this paper will compare ground based active optical sensor data collection with UAVs imagery for site-specific $\mathrm{N}$ management.

The growing web-based technology has completely transferred the geospatial technologies like GIS from desktop to web-based geo-spatial system. The data from different users of different regions help to work with updated spatial data with large coverage $\operatorname{area}^{[15]}$. The main advantage of this system is easy availability, accessibility and usability of the spatial data. According to Iftikhar and Pedersen ${ }^{[16]}$, xml-based data exchange was proposed which was mainly focused on the need of data exchanges between the farm computer and devices and among farmers' contractors, suppliers and advisory services. Also, the GIS software is an effective tool for developing yield maps and elevation maps and relating remotely sensed data to each other for spatial analysis. The effectiveness of tools such as GIS needs great amount of effort, training and experience ${ }^{[17]}$ Most of the GIS packages offer many functions with less value to agricultural application and are more expensive than the software packages developed by Agri-Logic Inc., AGRIS corporation, John Dere, Precision Farming group, etc. This software offers more flexibility for agricultural data. This supports the necessity of development of integration tools and decision support system for agricultural data ${ }^{[18]}$. Lack of better data standards prohibits the future use of resulting information without making any changes and manual data input ${ }^{[19]}$. There are no specific data standards for uploading the data into web and there is a lack of good visualizing and analyzing tools where farmers can extract an insight and take cost-effective crop management decisions. Presently available tools and techniques require an extra effort and time for separating the data and uploading it to the web depending upon the volume of data. The results of this study are significant because the precision agriculture data from different regions and farmers can be integrated into one to generate a general idea for making farming decisions. The developed technique is simple and easily accessible for visualizing and analyzing spatial data. The proposed tool does not require advanced skill and knowledge such as complicated software GIS. The web-based platform does not utilize extra space in personal computer and can be accessed from any place with internet access.

\section{Experimental design}

The study was conducted in Mississippi State University research field (Latitude: $33.470 \mathrm{~N}$ and Longitude: $88.763 \mathrm{~W}$ ). The total area of the corn field was 0.8 hectares. The corn field was sowed with DeKalb Brand-DKC67-72 variety at 32000 kernels per acre on April 13, 2017. The plantation design was a randomized complete block with four treatments and four replicates. The plots were 12 rows wide at 38 " spacing and were $125 \mathrm{ft}$. in length. There was a $10 \mathrm{ft}$ alley in between each plot (Figure 1). The plot was fertilized with nitrogen $(\mathrm{N})$ at the rates of $0,80,160$, and $240 \mathrm{lb}$. N/acre as a 50/50 split application with the first half applied at V1 April 1, 2017 and the $2^{\text {nd }}$ half of the rate applied at V6 on May 16, 2017. The $\mathrm{N}$ source was liquid UAN (urea-ammonium nitrate) $32 \% \mathrm{~N}$ applied with an applicator equipped with coulters and liquid knives spaced 9" from one side of each corn row and 3" deep. Corn was harvested with a two-row plot combine with an automated weighing system on August 24, 2017.

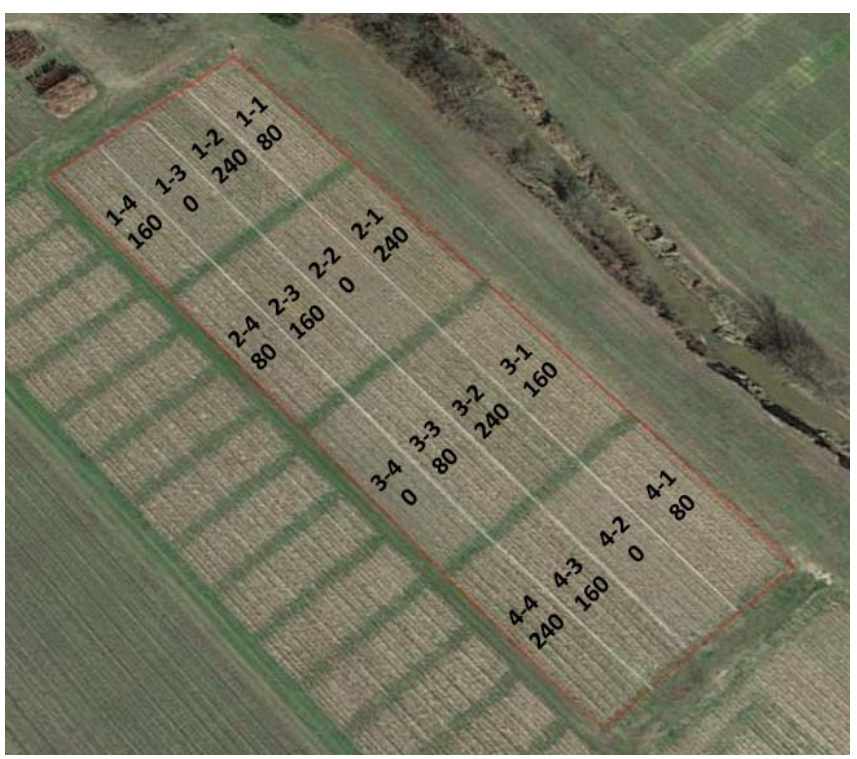

Figure 1 Corn field with treatment blocks 


\section{Material and methods}

GreenSeeker field sensor and Micasense sensor for UAVs was used to evaluate the Normalized Difference Vegetation Index. The UAVs sensor readings were taken on May 06, 2017 and June 09, 2017. Multiple band preprocessed digital data were provided by the Geosystems Research Institute, Mississippi State University for each date (Table 1).

Table 1 Spectral bands of digital image

\begin{tabular}{ccc}
\hline Bands & Name & Spectral range (NM) \\
\hline 1 & Blue & $440-510$ \\
2 & Green & $520-590$ \\
3 & Red & $630-685$ \\
4 & Red Edge & $690-730$ \\
5 & Near-Infrared & $760-850$ \\
\hline
\end{tabular}

We decided to use ArcGIS (ver 10.3) to further process the data and determine the corresponding NDVI values for different blocks and treatments. Image analysis tool available in ArcGIS was used to ascertain the NDVI values from the combinations of band rather than using raster calculator. The image analysis directly gives the scientific output. Whereas, raster calculator requires formula input which is a tedious process. Then, calculated the NDVI-Red and the NDVI-RedEdge with Red band and Near-Infrared (NIR) band and NDVI-Red and RedEdge band respectively with the help of image analysis tool. The computational formula for NDVI-Red ${ }^{[20]}$ and NDVI-Red Edge ${ }^{[21]}$ are shown in Equations (1) and (2), respectively.

$$
\begin{aligned}
\mathrm{NDVI}_{\text {red }} & =\frac{\mathrm{NIR}-\text { Red }}{\mathrm{NIR}+\text { Red }} \\
\mathrm{NDVI}_{\text {Red Edge }} & =\frac{\mathrm{NIR}-\text { Red Edge }}{\mathrm{NIR}+\text { Red Edge }}
\end{aligned}
$$

Then, the values were exported to Microsoft ${ }^{\circledR}$ Excel $^{\circledR} 2013$ for regression analysis on SAS. PROC REG procedure was used for the analysis. Statistical analysis also included the summary of statistical parameters for each treatment. Variance of treatments was studied with the help of t-Test for $95 \%$ confidence interval.

Another handheld NDVI sensor, GreenSeeker, developed by Trimble Inc was used to evaluate the plant condition. The sensor emits its own light which is incident on the plant. And then, measures the reflected back red and infrared range of light. The value obtained from the sensor are in terms of NDVI reading that ranges from 0.00 to 0.99 (NDVI value ranges from -1 to +1 ). There is a trigger that is pushed accordingly for continuous or individual readings. We took 10 random readings of NDVI with GreenSeeker from each block. First set of data readings was taken on May 20, 2017 and the second set on June 9, 2017. We had planned to take the first set of data on the same date as of UAVs. But due to some technical issues that did not become possible. In total, 160 readings were taken for both the dates. The readings were manually recorded in note book along with the geospatial location. We also used Trimble Juno t41/5 rugged handheld computer to record the latitude and longitude of each point. Again, the note book readings were manually transferred to excel sheet before plotting the values in ArcGIS with the spatial locations. Following that, they were converted to shapefile (ESRI file format). We then used "ADD XY data" tool for plotting the values. The NDVI values were correlated with the respective treatment blocks. Exploratory analysis of the sensor data was performed in SAS similar to UAVs data that included regression analysis and summary of statistical parameters for each treatment. It was not possible to investigate the significant relationships of amount of $\mathrm{N}$ application and NDVIs. Further data collection is required to determine and validate exactly how amount of $\mathrm{N}$ affects biomass content at different growth stages.

\section{Results}

\subsection{Effect of treatment on NDVI values}

Descriptive statistical analysis was used to analyze the NDVI values of two different growth stages for four different $\mathrm{N}$ application rates (trials). Table 1 and Table 2 compares the summary statistics for two different vegetative stages. The mean, minimum and maximum NDVI values along with standard deviation were calculated for each trial plot. It is apparent from the Table 2 and Table 3 that the average NDVI value has increased with increasing amount of $\mathrm{N}$ application for both the dates (Vegetative Stages). From the table, it can be seen that the maximum NDVI value 0.86 is for the application rate of $240 \mathrm{lb}$./acre (May 20, 2017) and 80 and $160 \mathrm{lb}$./acre (June 9, 2017). Whereas, lowest NDVI value 0.4 (May 20, 2017) and 0.55 (June 9, 2017 ) is for no $\mathrm{N}$ application respectively. These Tables (2 and 3 ) are quite self-revealing that there was clear distinction between applied and not applied, but there was no significant difference in different application rates.

Table 2 Summary of statistical parameters for each treatment by field sensor (20 May, 2017)

\begin{tabular}{cccccc}
\hline $\begin{array}{c}\text { Amount of } n \\
\text { lb./acre }\end{array}$ & $\begin{array}{c}\text { Average } \\
\text { (NDVI) }\end{array}$ & $\begin{array}{c}\text { Min } \\
\text { (NDVI) }\end{array}$ & $\begin{array}{c}\text { Max } \\
\text { (NDVI) }\end{array}$ & SD & $\begin{array}{c}\text { Number of } \\
\text { data }\end{array}$ \\
\hline 0 & 0.54 & 0.4 & 0.72 & 0.06 & 40 \\
80 & 0.72 & 0.47 & 0.84 & 0.08 & 40 \\
160 & 0.74 & 0.63 & 0.84 & 0.06 & 40 \\
240 & 0.76 & 0.5 & 0.86 & 0.08 & 40 \\
\hline
\end{tabular}

Table 3 Summary of statistical parameters for each treatment by field sensor (09 June, 2017)

\begin{tabular}{cccccc}
\hline $\begin{array}{c}\text { Amount of } n \\
\text { lb./acre }\end{array}$ & $\begin{array}{c}\text { Average } \\
\text { (NDVI) }\end{array}$ & $\begin{array}{c}\text { Min } \\
\text { (NDVI) }\end{array}$ & $\begin{array}{c}\text { Max } \\
\text { (NDVI) }\end{array}$ & SD & $\begin{array}{c}\text { Number of } \\
\text { data }\end{array}$ \\
\hline 0 & 0.73 & 0.55 & 0.8 & 0.05 & 40 \\
80 & 0.80 & 0.63 & 0.86 & 0.05 & 40 \\
160 & 0.82 & 0.76 & 0.86 & 0.02 & 40 \\
240 & 0.80 & 0.78 & 0.85 & 0.1 & 40 \\
\hline
\end{tabular}

4.2 Characterized relationships between UAVs-NDVI and GreenSeeker-NDVI

The NDVI (green-ness) by the field sensor and UAVs sensors are indicator for crop-nutrition. A positive correlation (R-square $=0.34$ ) was found between UAVs-NDVI values and GreenSeekerNDVI values. The scatter plot between NDVI values of UAVs and GreenSeeker in Figure 1 shows reasonable positive correlation. The marked observation to emerge from the data comparison: both the NDVI showed similar trend with significant offset values. This analysis provides considerable insight into NDVI by field sensor and UAVs as indicator of crop-nutrition. The result reinforces the usefulness of UAVs sensors as successful tool for gathering post processing information in the field of agriculture.

\subsection{Relationship between NDVI and N application rate at two} different growth stages.

A separate analysis with $\mathrm{N}$ application rate and NDVI-RedEdge and NDVI-Red as factors confirmed that the effect 
of amount of $\mathrm{N}$ application on NDVI values are more prominent on later growth stages (Table 4). The analysis of UAVs images for May 3, 2017 dissects that none of the variability in NDVI was explained by the amount of $\mathrm{N}$ applied. At early growth stages, the correlation between $\mathrm{N}$ and NDVI-RedEdge and NDVI-Red is worth noting because no significant differences were found between both RedEdge and Red NDVIs. However, at the later vegetative stage, there was a significant positive correlation between GreenSeeker-NDVI values and $\mathrm{N}$ application. 46 percent of variation in NDVI is explained by the amount of $\mathrm{N}$ applied.

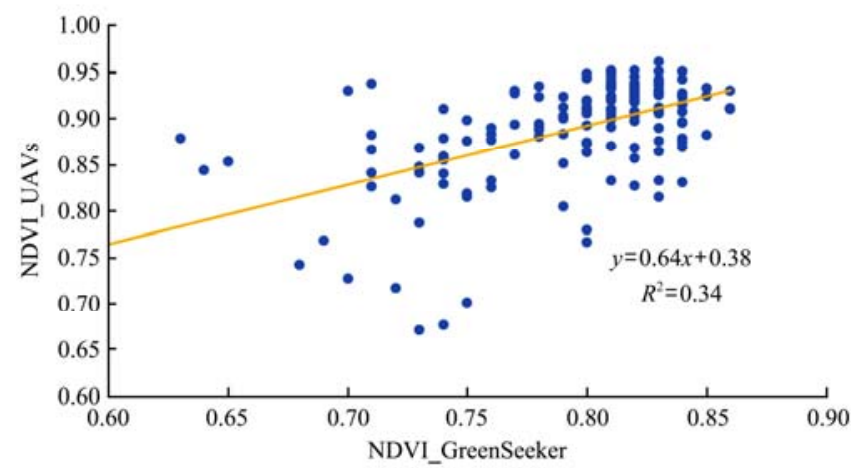

Figure 2 Relationship between ground field sensor NDVI and NDVI derived from UAVs imagery data

Table 4 Regression coefficients $\left(R^{2}\right)$ and the models of the relationship between $\mathrm{N}$ application rate and NDVIs

\begin{tabular}{ccc}
\hline & Rededge & Red \\
\hline & NDVI $=3 \mathrm{E}-05 \mathrm{~N}(\mathrm{lb} . / \mathrm{ac})+$ & $\mathrm{NDVI}=-3 \mathrm{E}-05 \mathrm{~N}(\mathrm{lb} . / \mathrm{ac})+$ \\
UAVs (MAY 3) & 0.0954 & 0.1868 \\
& $R^{2}=0.0043$ & $R^{2}=0.0006$ \\
GreenSeeker & $\mathrm{NDVI}=0.0008 \mathrm{~N}(\mathrm{lb} . / \mathrm{ac})+$ \\
(MAY 20) & 0.5876 \\
& & $R^{2}=0.46$ \\
\hline
\end{tabular}

\subsection{Treatment comparison using Analysis of Variance}

For the purpose of assessment, how the combination of different $\mathrm{N}$ treatments improved the corn biomass content $\mathrm{t}$-test at 0.05 percent significance level. We can observe from the Table 5 , there is strong significant difference between no $\mathrm{N}$ treatments and $\mathrm{N}$ treatments. On the other hand, there is less or no any significant difference in the NDVI values for increased rate of $\mathrm{N}$. From the result, it is clear that increasing the $\mathrm{N}$ rate after certain extent will not make any difference in the biomass content.

Table 5 P-values for the test of significant different $\mathrm{N}$ rates; analysis of variance $(\boldsymbol{p}<0.05)$

\begin{tabular}{|c|c|c|c|}
\hline & $\mathrm{NDVI}_{-} 0$ & NDVI_ 80 & NDVI_ 160 \\
\hline \multicolumn{4}{|l|}{$\mathrm{NDVI}_{-} 0$} \\
\hline NDVI_ 80 & $\begin{array}{c}\text { Strong significant } \\
\text { different }(1.284 \mathrm{e}-07)\end{array}$ & & \\
\hline NDVI ${ }_{-} 160$ & $\begin{array}{c}\text { Strong significant } \\
\text { different }(1.273 \mathrm{e}-13)\end{array}$ & $\begin{array}{c}\text { Not significant different } \\
(0.01024)\end{array}$ & \\
\hline NDVI_ 240 & $\begin{array}{c}\text { Strong significant } \\
\text { different }(1.315 \mathrm{e}-13)\end{array}$ & $\begin{array}{l}\text { Weak significant } \\
\text { different }(0.006102)\end{array}$ & $\begin{array}{c}\text { No difference } \\
\quad(0.9098)\end{array}$ \\
\hline
\end{tabular}

\section{Discussion}

UAVs is a very useful tool for monitoring the changes in crop status and yield estimation over the growing period and identifying the input requirements to maximize the yield ${ }^{[22,23]}$. Several authors have expressed about further advances in real time application of UAVs for ease of farmers to manage the field crop $^{[24,25]}$. As mentioned in the introduction, the main hypothesis of this study is UAVs data derived imagery significantly correlates with biomass content of the crop and can be used for real time or near real time corn $\mathrm{N}$ deficiency management techniques. The study was also planned to compare the UAVs emanated NDVI to already proven technology active ground sensors ${ }^{[26,27]}$.

The current study found that UAVs assessed NDVI are also good indicator of crop nutrition. The result of the statistical data analysis showed that NDVI values increased with the amount of N applied. Another important finding was that this study did not find any significant difference between the higher throughput of the $\mathrm{N}$. This results match those observed in earlier studies ${ }^{[28,29]}$. The result of anova demonstrated two things; first, the $\mathrm{N}$ application amount resulted in higher NDVI values to a certain level. Second, there were not any significant differences with the further increase of $\mathrm{N}$ rate. In accordance with the present results, previous studies have demonstrated that there is no any considerable increase in the yield with top dressing of $\mathrm{N}^{[29]}$.

The potential of UAVs acquired NDVI and ground sensor has been compared effectively. Various studies have argued for the early vegetative stage (V6) of crops for substituting the insufficient $\mathrm{N}^{[30,31]}$. Conversely, the NDVI value increases with the plant growth. At early growth state, the average UAVs-NDVI values are lesser compared to the GreenSeeker-NDVI values for the same plot. We speculate this might be due to dominant reflection of soil back to the UAVs sensor. The rather contradictory result for ground sensor might be due to recording of data directly over the plant minimizing the effect of soil reflectance.

Our work clearly has some limitations. Despite this we believe our work could be a spring board for further validating the use of UAVs derived NDVIs for web based and real time application in crop production. The most important limitation is a result of fact that there were not sufficient data to make a concrete conclusion. The current study was limited by the number of UAVs flights due to lack of better coordination between geospatial research institute responsible for flights. However, given the small sample size caution must be exercised for the analysis of the data.

The study has gone some way towards enhancing our understanding of significance of UAVs imagery for real time crop management decisions. The research has proved that there is good correlation of UAVs-NDVI with the biomass content and in rage with widely used active crop sensing technology. The present findings might help to estimate the optimum amount of $\mathrm{N}$ application for the corn crop. This could eventually lead to maximize profits through input reduction.

\section{Conclusions}

It is difficult to arrive at any concrete conclusion, but we have obtained comprehensive results proving that UAVs derived NDVI and ground based sensor NDVI both indicates the level of $\mathrm{N}$ in the corn crop. By using the available data, we tested there is significant relationship between UAVs and active optical sensors. More generally, these basic findings are consistent with research showing that UAVs as a platform mounted with infrared sensors can be more feasible to identify biomass content without compromising the accuracy of ground based sensors. Our data suggests that we still have to go long way to further validate the findings. Future research should consider different crop fields and increase the sample size and number of flights. 


\section{Acknowledgement}

The fund for this research has been provided by Special Research Initiative, Mississippi Agricultural and Forestry Experiment Station (MAFES), Mississippi State University, Mississippi State, MS, USA.

\section{[References]}

[1] Cambardella, C. A., Karlen, D. L. Spatial Analysis of Soil Fertility Parameters. Precision Agriculture, 1999; 1, 5-14. Retrieved from https://link.springer.com/content/pdf/10.1023\%2FA\%3A1009925919134.p df

[2] Cook, S. E., Bramley, R. G. V. Precision agriculture- opportunities, benefits and pitfalls of site-specific crop management in Australia. Australian Journal of Experimental Agriculture, 1998; 38(7): 753-763.

[3] Gomide, R. L., Inamasu, R. Y., Queiroz, D. M., Mantovani, E. C., Santos, W. F. An automatic data acquisition and control mobile laboratory network for crop production systems data management and spatial variability studies in the Brazilian center-west region. In 2001 ASAE Annual Meeting (p. 1). American Society of Agricultural and Biological Engineers.

[4] Adamchuk, V. I., Hummel, J. W., Morgan, M. T., Upadhyaya, S. K. On-the-go soil sensors for precision agriculture. Computers and Electronics in Agriculture, 2004; 44(1): 71-91.

[5] Wang, N., Zhang, N., Wang, M. Wireless sensors in agriculture and food industry-Recent development and future perspective. Computers and Electronics in Agriculture, 2006; 50(1): 1-14.

[6] Jenkins, D., Vasigh, B. The Economic Impact of Unmanned Aircraft Systems Integration in the United States. Association for Unmanned Vehicle Systems International, 2013; (March), 1-40. Retrieved from http://www.auvsi.org/econreport

[7] Atzberger, C. Advances in remote sensing of agriculture: Context description, existing operational monitoring systems and major information needs. Remote Sensing, 2013; 5(2): 949-981. https://doi.org/10.3390/rs5020949

[8] Kamilaris, A., Kartakoullis, A., Prenafeta-Boldú, F. X. A review on the practice of big data analysis in agriculture. Computers and Electronics in Agriculture, 2017; 143(January): 23-37. https://doi.org/10.1016/ j.compag.2017.09.037

[9] Sawant, M., Urkudeb, R., Jawale, S. Organized Data and Information for Efficacious Agriculture Using PRIDE ${ }^{\mathrm{TM}}$ Model. International Food \& Agribusiness Management Review, 2016; 19, 115-130. Retrieved from https://ifama.org/resources/Documents/v19ia/ 620150151.pdf

[10] Jeppesen, J. H., Ebeid, E., Jacobsen, R. H., Toftegaard, T. S. Open geospatial infrastructure for data management and analytics in interdisciplinary research. Computers and Electronics in Agriculture, 2018; 145(November 2017): 130-141. https://doi.org/10.1016/j.compag. 2017.12.026

[11] McBratney, A. B., Whelan, B., Ancev, T., Bouma, J. Future Directions of Precision Agriculture. Precision Agriculture, 2005; 6(July 2004), 7-23. https://doi.org/http://dx.doi.org/10.1007/s11119-005-0681-8

[12] Yadav, R. Big Data Meets Small Sensors in Precision Agriculture. International Journal of Computer Applications, 2015; 1-4.

[13] Řezník, T., Lukas, V., Charvát, K., Charvát, K., Křivánek, Z., Kepka, M., ... Řezníková, H. Disaster Risk Reduction in Agriculture through Geospatial (Big) Data Processing. ISPRS International Journal of Geo-Information, 2017; 6(8): 238. https://doi.org/10.3390/ijgi6080238

[14] Lan, Y. Bin, Chen, S. De, Fritz, B. K. Current status and future trends of precision agricultural aviation technologies. International Journal of Agricultural and Biological Engineering, 2017; 10(3): 1-17. https://doi.org/10.3965/j.ijabe.20171003.3088
[15] Charvat, K., Kafka, S., Holy, S., Horak, P., Cepicky, J., Kocáb, M., Cajthaml, T. This is not a peer-reviewed article. Spatial Data Management. In Spatial Data Management, 2006; pp. 1-10. Retrieved from http://elibrary.asabe.org/azdez.asp?JID=1\&AID=21960\&CID= canr2006\&v $=\& \mathrm{i}=\& \mathrm{~T}=1 \&$ refer $=7$ \&access $=\&$ dabs $=\mathrm{Y}$

[16] Iftikhar, N., Pedersen, T. B. Flexible exchange of farming device data Computers and Electronics in Agriculture, 2011; 75(1): 52-63.

[17] Kitchen, N. R., Snyder, C. J., Franzen, D. W., Wiebold, W. J. Educational needs of precision agriculture. Precision Agriculture, 2002; 3(4): 341-351.

[18] Zhang, N., Wang, M., Wang, N. Precision agriculture-a worldwide overview. Computers and Electronics in Agriculture, 2002; 36(2-3): 113-132.

[19] Steinberger, G., Rothmund, M., Auernhammer, H. Mobile farm equipment as a data source in an agricultural service architecture. Computers and Electronics in Agriculture, 2009; 65(2): 238-246.

[20] Rouse, J. W., Haas, R. H., Schell, J. A., Deering, D. W., Harlan, J. C. 1974. AND RETROGRADATION (GREENWAVE EFFECT) I OF NATURAL VEGETATION. Retrieved from http://citeseerx.ist.psu.edu/ viewdoc/download?doi=10.1.1.464.7884\&rep=rep1\&type=pdf

[21] Barnes, E., Clarke, T., Richards, S., Colaizzi, P., Haberland, J., Kostrzewski, M., ... Moran, M. (n.d.). COINCIDENT DETECTION OF CROP WATER STRESS, NITROGEN STATUS AND CANOPY DENSITY USING GROUND-BASED MULTISPECTRAL DATA. Retrieved from https://naldc.nal.usda.gov/download/4190/PDF

[22] Schut, A. G. T., Traore, P. C. S., Blaes, X., de By, R. A. Assessing yield and fertilizer response in heterogeneous smallholder fields with UAVs and satellites. Field Crops Research, 2018; 221(June 2017): 98-107. https://doi.org/10.1016/j.fcr.2018.02.018

[23] Zhou, X., Zheng, H. B., Xu, X. Q., He, J. Y., Ge, X. K., Yao, X., ... Tian, Y. C. Predicting grain yield in rice using multi-temporal vegetation indices from UAV-based multispectral and digital imagery. ISPRS Journal of Photogrammetry and Remote Sensing, 2017; 130, 246-255. https://doi.org/10.1016/j.isprsjprs.2017.05.003

[24] Costa, F. G., Ueyama, J., Braun, T., Pessin, G., Osorio, F. S., Vargas, P. A. The use of unmanned aerial vehicles and wireless sensor network in agricultural applications. 2012 IEEE International Geoscience and Remote Sensing Symposium, 2012; 5045-5048. https://doi.org/10.1109/ IGARSS.2012.6352477

[25] Reinecke, M., Prinsloo, T. The influence of drone monitoring on crop health and harvest size. 2017 1st International Conference on Next Generation Computing Applications, NextComp 2017, 2017; 5-10. https://doi.org/10.1109/NEXTCOMP.2017.8016168

[26] Kitchen, N. R., Sudduth, K. A., Drummond, S. T., Scharf, P. C., Palm, H. L., Roberts, D. F., Vories, E. D. Ground-based canopy reflectance sensing for variable-rate nitrogen corn fertilization. Agronomy Journal, 2010; 102(1): 71-84. https://doi.org/10.2134/agronj2009.0114

[27] Sharma, L. K., Bu, H., Denton, A., Franzen, D. W. Active-optical sensors using red NDVI compared to red edge NDVI for prediction of corn grain yield in north Dakota, U.S.A. Sensors (Switzerland), 2015; 15(11): 27832-27853. https://doi.org/10.3390/s151127832

[28] Ratanoo, R., Kumar, S., Dhaka, A. K., Rolaniya, L. Precision Nitrogen Management Based on NDVI and in-Season Estimates of Response Index in Wheat, 2018; 7(4): 393-399.

[29] Walsh, O. S., Shafian, S., Christiaens, R. J. Evaluation of Sensor-Based Nitrogen Rates and Sources in Wheat, 2018.

[30] Mo-, A. T. N. Variable-Rate Nitrogen Fertilizer Application for Corn Using In-field Sensing of Leaves or Canopy, 2009; (August): 1-6.

[31] Raun, W. R., Solie, J. B., Stone, M. L., Martin, K. L., Schepers, J. S. Johnson, G. V. Optical Sensor-Based Algorithm for Crop Nitrogen Fertilization *, 2005; (October 2004): 2759-2781. https://doi.org/ $10.1080 / 00103620500303988$ 